\title{
Topographical changes revealed by high-resolution airborne LiDAR data: The 1999 Tsaoling landslide induced by the Chi-Chi earthquake
}

\author{
Rou-Fei Chen ${ }^{a, b, *}$, Kuo-Jen Chang ${ }^{b}$, Jacques Angelier ${ }^{\text {a,c }}$, Yu-Chang Chan ${ }^{\text {b }}$, \\ Benoît Deffontaines $^{\mathrm{d}}$, Chyi-Tyi Lee ${ }^{\mathrm{e}}$, Ming-Lang Lin ${ }^{\mathrm{f}}$ \\ a Observatoire Océanologique de Villefranche-sur-mer, Université P. \& M. Curie, Géosciences Azur, Villefranche-sur-Mer, France \\ ${ }^{\mathrm{b}}$ Institute of Earth Sciences, Academia Sinica, P. O. Box 1-55 Nankang, Taipei 115, Taiwan \\ ${ }^{\mathrm{c}}$ Institut Universitaire de France, France \\ d Institut Francilien des Géosciences, Université de Marne-la-Vallée Cité Descartes, Champs sur Marne, France \\ ${ }^{\mathrm{e}}$ Institute of Geophysics, National Central University, Chung-Li, Taiwan \\ ${ }^{\mathrm{f}}$ Department of Civil Engineering, National Taiwan University, Taipei, Taiwan
}

Accepted 11 September 2006

\begin{abstract}
The 1999 Chi-Chi earthquake triggered the catastrophic Tsaoling landslide in central Taiwan. We mapped the landslide area and estimated the landslide volume, using a high-resolution digital elevation model from airborne LiDAR (Light Detection And Ranging), aerial photographs and topographic maps. The comparison between scar and deposit volumes, about $0.126 \mathrm{~km}^{3}$ and $0.150 \mathrm{~km}^{3}$ respectively, suggests a coseismic volume increase of $19 \%$ due to decompaction during landsliding. In July 2003, the scar and deposit volumes were about $0.125 \mathrm{~km}^{3}$ and $0.110 \mathrm{~km}^{3}$ respectively. These estimates suggest that 4 years after the event, the volume of landslide debris removed by river erosion was nearly $0.040 \mathrm{~km}^{3}$. These determinations are confirmed by direct comparison between the most accurate topographic models of the post-landslide period, indicating a very high erosion rate at the local scale $\left(0.01 \mathrm{~km}^{3} /\right.$ year $)$ for the deposit area of the landslide. Such a large value highlights the importance of landslide processes for erosion and long-term denudation in the Taiwan mountain belt.
\end{abstract}

(C) 2006 Elsevier B.V. All rights reserved.

Keywords: LiDAR images; Remote sensing; Surface change; Tsaoling Landslide; Chi-Chi earthquake; Taiwan

\section{Introduction}

The island of Taiwan is located between the Philippine Sea plate and Eurasian plate (Fig. 1a), with the two

\footnotetext{
* Corresponding author. Institute of Earth Sciences, Academia Sinica, P. O. Box 1-55 Nankang, Taipei 115, Taiwan. Tel.: +886 27839910x412; fax: +886227839871 .

E-mail address: roufei@earth.sinica.edu.tw (R.-F. Chen).
}

opposite-verging subduction systems of the Ryukyu arctrench and Luzon arcs to the east and south respectively. Taiwan is one of the regions on Earth with the highest seismic activity. The results of GPS studies revealed a rate of plate convergence of $8.2 \mathrm{~cm} /$ year along the azimuth $306^{\circ}$ (Yu et al., 1997). In Taiwan, the landslide hazard reaches high levels in the mountainous part of the island where earthquakes are frequent and typhoons (heavy rainfall) are common each year. More than $70 \%$ of 


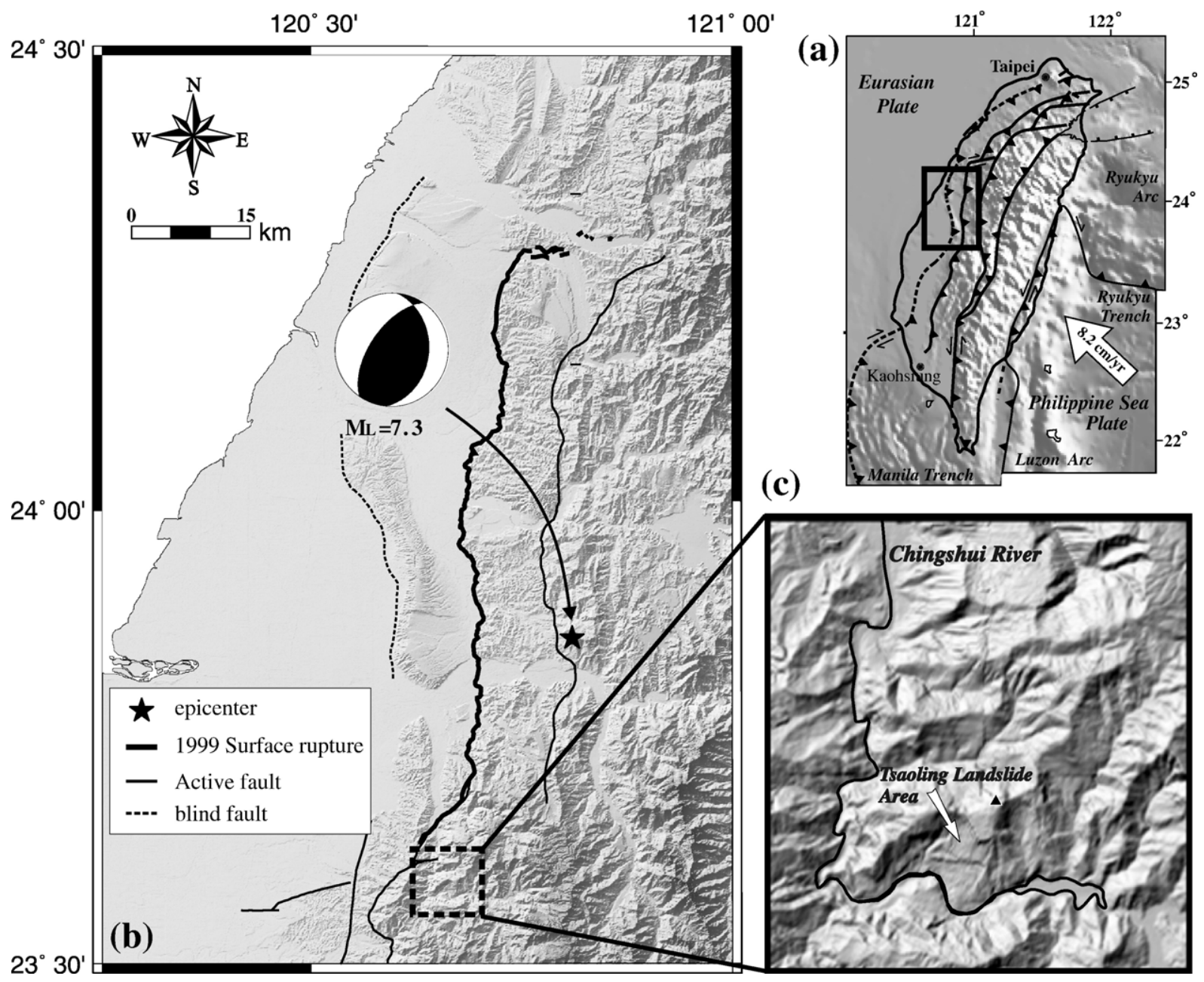

Fig. 1. (a) Geodynamic setting of Taiwan; small rectangle indicates location of (b) in central-west Taiwan. (b) Map of the surface rupture of the Chelungpu Fault, 1999 Chi-Chi earthquake; epicentre as solid star; focal mechanism of the mainshock added with usual beachball-like projection; small dashed frame indicates location of the study area shown in (c). (c) Shaded topographic map of the Tsaoling region before 1999, based on the $198940 \times 40$ m DEM.

the annual rainfall occurs in the summer season, between July and September (Water Resources-Agency, 2002).

During the 1999 Chi-Chi earthquake $\left(M_{\mathrm{L}}=7.3\right)$, abundant landslides were triggered in central Taiwan on the night (01:47 local time) of 21 September. This earthquake, the most destructive one of the 20th century in Taiwan, killed more than 2450 persons and resulted in widespread damage in central Taiwan (Chung and Shin, 1999; Ma et al., 1999). The Chi-Chi earthquake was caused by movement on the Chelungpu thrust fault, which had been seismically active about 150 years ago according to informal written record (Chen et al., 2001a, b). A more than $90 \mathrm{~km}$-long surface rupture developed (Fig. 1b), involving thrusting and left-lateral components (Central Geological Survey, 1999; Kao and Chen,
2000; Angelier et al., 2001; Chen et al., 2001a,b). The vertical offsets averaged $2 \mathrm{~m}$ along the southern half of the Chelungpu Fault and about $4 \mathrm{~m}$ along the northern segment; horizontal offsets up to $10 \mathrm{~m}$ were observed along the northern part of major fault (Chen et al., 2001a,b; Lee et al., 2002).

Earthquake shaking is a major agent of landslide generation, with the largest earthquakes capable of triggering thousands of landslides throughout areas up to $260,000 \mathrm{~km}^{2}$ (Keefer, 1984). Among all the landslides triggered by the Chi-Chi earthquake, the Tsaoling slope failure involved the largest area and volume displacement. A study of SPOT images (Liao, 2000) indicated that the Chi-Chi earthquake had triggered 9272 landslides covering a total area of $128 \mathrm{~km}^{2}$. 
Tsaoling is located in the valley of the Chingshui River (Fig. 1c), a tributary of the Choshui River, the largest river on Taiwan. The Chingshui watershed area under investigation in the present study shows a triangular to trapezoidal slope domain, with the crown of the landslide to the northeast at the top of Tsaoling Mountain (elevation $1235 \mathrm{~m}$ ) and a base (the slide toe) to the southwest at the Chingshui River (elevation $500 \mathrm{~m}$ ). At the site of the Tsaoling landslide, about $30 \mathrm{~km}$ southwest of the Chi-Chi epicenter (Fig. 1b), at least five major dip slope failures triggered by rain or earthquakes have occurred between 1862 and 1999 on the southwest slope of the Tsaoling Mountain (see details and references in Table 1).

In Taiwan, aerial photograph interpretation and mapping are routinely performed by the Agricultural and Forestry Aerial Survey Institute of Taiwan. During recent years, the most commonly used material has been the digital elevation models (DEM) based on aerial photos with a $40 \times 40 \mathrm{~m}$ mesh resolution (Central for Space and Remote Sensing Research, 1989). The DEM establishment facilitated neotectonic and quantitative geomorphology studies in Taiwan.

The objectives of this study are to identify the terrain characteristics associated with the 1999 Tsaoling landslide and to determine the total volume of earthquake-induced landslide material produced over time. For our morphometric analysis we used the high resolution data issued from the airborne LiDAR (Light Detection and Ranging), a new technology that uses a transmitted laser beam to reconstruct the morphology in detail (Wehr and Lohr, 1999; Priestnall et al., 2000; Joinville et al., 2002; Charlton et al., 2003; White and Wang, 2003). Comparing different sets of data from different years, we estimated the landslide-related mass transfer and subsequent erosion. Note that the accuracy of these comparisons could not reflect the high resolution of the recent LiDAR-derived DEM, because limitations in resolution were imposed by the prelandslide DEMs derived from more conventional analyses (satellite images, aerial photographs and topographic maps).

\section{Historical landslide events at Tsaoling}

The Tsaoling area, characterised by mountainous topography, is located in the Foothill Region of Central Taiwan (Fig. 1b-c). The occurrence of successive landslides and related destruction in the Tsaoling area has been documented for the past 140 years. Historical catastrophic dip slope failures have repeatedly occurred: the first recorded event occurred in 1862 (triggered by an earthquake), then in 1941 (triggered by an earthquake), 1942 (triggered by heavy rainfall), 1979 (triggered by heavy rainfall), and 1999 (triggered by the Chi-Chi earthquake). Debris of the landslides repeatedly dammed the Chingshui River. Breakage of landslide dams from previous landslide events took place in 1898, 1951, and 1979. The major historical Tsaoling landslides are summarized in Table 1, with appropriate references (Tai-Pei Observatory, 1942; Kamai, 1942; Chang, 1951; Hsu and Leung, 1977; Hung, 1980; Lee et al., 1993; Liao, 2000; Hung et al., 2002; Chen et al., 2003; Chigira et al., 2003).

\subsection{Landslide events in 1862 and 1898}

The first reported event of dip-slope failure and subsequent formation of a landslide dam occurred on June 6,1862 . This landslide may have been triggered by the major 1862 earthquake with estimated magnitude between $M_{\mathrm{L}}=6.0$ and $M_{\mathrm{L}}=7.0$, which occurred in the

Table 1

Historical events in the Tsaoling landslide area

\begin{tabular}{|c|c|c|c|c|c|}
\hline \multirow[t]{2}{*}{ Time } & \multirow[t]{2}{*}{ Trigger } & \multicolumn{3}{|l|}{ Landslide process } & \multirow[t]{2}{*}{ Ref. } \\
\hline & & Slide volume $\left(\mathrm{km}^{3}\right)$ & Dam height (m) & Effects & \\
\hline 1862 & Earthquake $\left(M_{\mathrm{L}}=6-7\right)$ & & & Formation of landslide dam & $1,2,5,9$ \\
\hline 1898 & Rainfall & & & Landslide dam breakage & $1,2,5,9$ \\
\hline 1941 & Earthquake $\left(M_{\mathrm{L}}=7.1\right)$ & $0.10-0.15$ & $70-140$ & 36 persons killed and formation of dam & $2,3,4,5,6,8,9$ \\
\hline 1942 & Rainfall (776 mm) & $0.15-0.20$ & $140-170$ & 1 person killed and growth of landslide dam & $2,3,4,5,6,8,9$ \\
\hline 1951 & Rainfall (770 mm) & 0.120 & $140-200$ & 137 persons killed and breakage of landslide dam & $3,4,5,6,8,9$ \\
\hline \multirow[t]{2}{*}{1979} & Rainfall (327 mm) & 0.026 & 90 & Formation of landslide dam & $5,6,8,9,10$ \\
\hline & Rainfall (624 mm) & 0.040 & & Landslide dam breakage & $5,6,8,9,10$ \\
\hline 1999 & Earthquake $\left(M_{\mathrm{L}}=7.3\right)$ & 0.126 & 45 & 39 persons killed and formation of dam & $7,8,9,10$ \\
\hline
\end{tabular}

Sources: 1. Tai-Pei Observatory (1942); 2. Kamai (1942); 3. Chang (1951); 4. Hsu and Leung (1977); 5. Hung (1980); 6. Lee et al. (1993); 7. Liao (2000); 8. Hung et al. (2002); 9. Chen et al. (2003); 10. Chigira et al. (2003). 
Chia-Yi and Tai-Nan region (Hsu, 1980). According to the description of an ordnance "Takezaki" topographic map ordered by the Japanese government in 1930 (at scale 1:50 000), the scarp was located at an approximate elevation of 750-770 $\mathrm{m}$, the elevation of Chingshui River bed being about $390 \mathrm{~m}$. The natural dam created by this landslide failed in 1898 after heavy rainfall (TaiPei Observatory, 1942).

\subsection{Landslide events in 1941, 1942 and 1951}

Another major earthquake $\left(M_{\mathrm{L}}=7.1\right)$, with epicentre at $23.40^{\circ} \mathrm{N}, 120.50^{\circ} \mathrm{E}, 10 \mathrm{~km}$ southeast of Chia-Yi city, induced the next major landslide on December 17, 1941. A rockslide involving a mass movement of more than $0.100-0.150 \mathrm{~km}^{3}$ occurred on the southwest flank of Tsaoling Mountain (Chigira et al., 2003). The crest of the landslide dam was estimated to be $70-200 \mathrm{~m}$ above the riverbed. Fig. 2a shows the landslide crosssection of the landslide with the sliding plane located at the boundary between the Cholan formation and the Chinshui shale. Heavy rainfall (3 days cumulative precipitation of $770 \mathrm{~mm}$ ) led to a reactivation of the landslide on August 10, 1942, with a formation of a larger natural dam at the same location as before. More than $0.100 \mathrm{~km}^{3}$ of the rock mass slid down the dip slope and the Chingshui River was dammed with debris. On May 18, 1951, following 5 days of rainfall with a cumulative precipitation of $776 \mathrm{~mm}$, the landslide dam failed by overtopping and caused serious damage in downstream valleys (Chang, 1951). This dam failure killed 137 army engineers, who were installing the spillway on top of the landslide dam, and $0.120 \mathrm{~km}^{3}$ of water was released (Hsu and Leung, 1977).

\subsection{Landslide events in 1979}

A heavy rainfall reactivated the landslide in 1979; two bridges were destroyed downstream. On August 15,

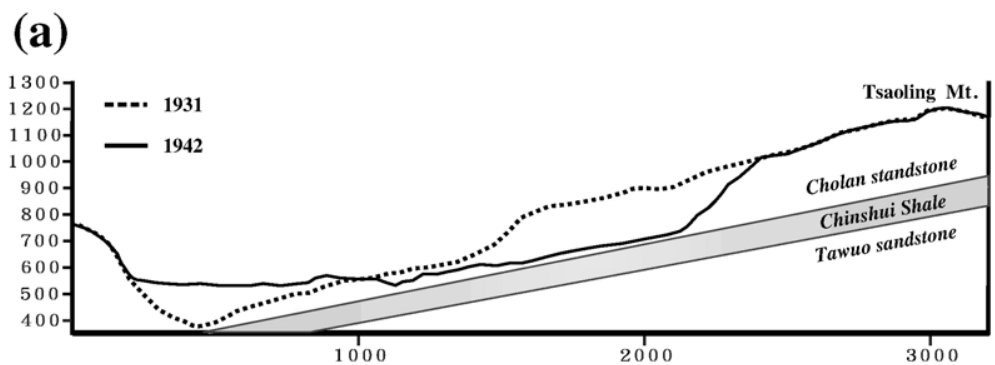

(b)

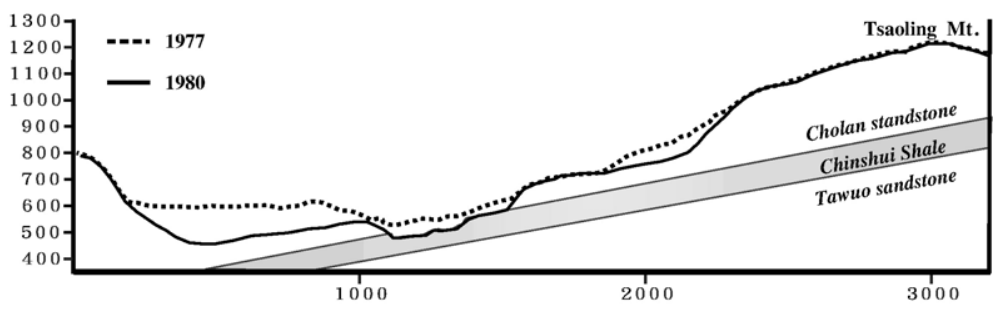

(c)

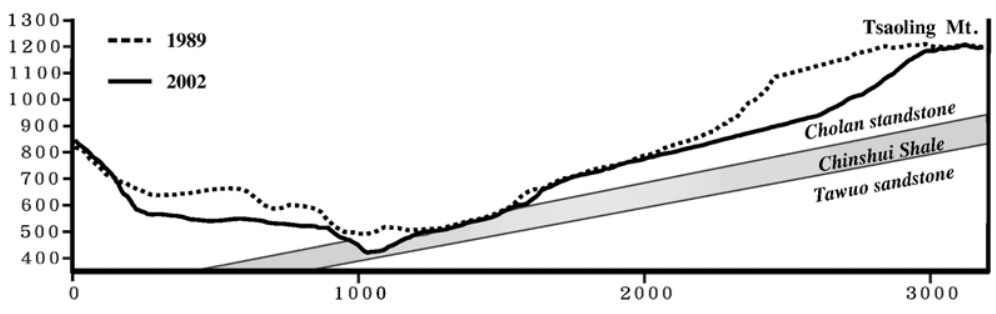

Fig. 2. Reconstructed cross-sections of the Tsaoling landslide. (a) Topographic profiles (based on topographic maps at scale 1/50 000) in 1931 (dotted line) and 1942 (solid line), i.e. before and after the 1941 Tsaoling event. (b) Topographic profiles (based on topographic maps at scale 1/25 000) before (dotted line) and after (solid line) the 1979 Tsaoling event. (c) Topographic profiles based on the $40 \times 40 \mathrm{~m} 1989$ DEM (dotted line) and the 2002 LiDAR mapping (solid line), i.e. before and after the 1999 Tsaoling landslide. 


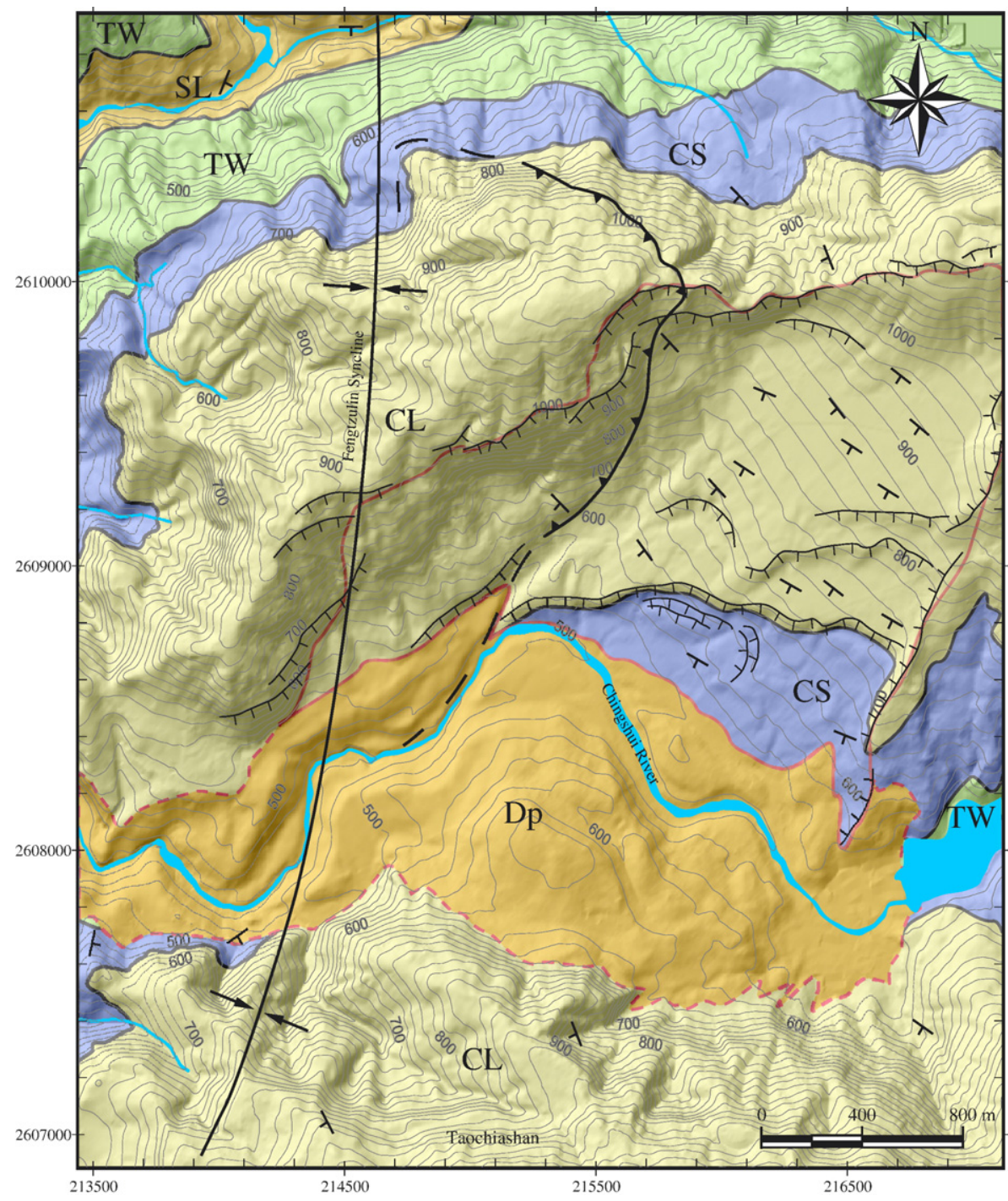

\section{LEGEND}
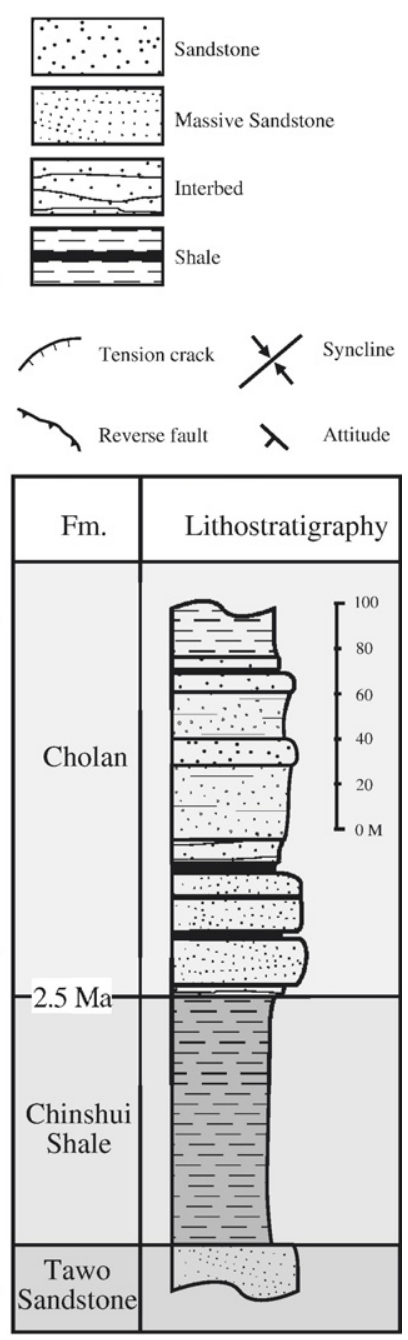

Fig. 3. Geological map and representative stratigraphic section of the study area. Shaded relief map of the Tsaoling region, with $25 \mathrm{~m}$ contour interval by the airborne-LiDAR-derived DEM. CL Cholan Formation (sandstone and shale); CS Chinshui Shale; TW Tawo sandstone; SL Shihliufeng shale and DP debris deposit.

1979, heavy rain caused the failure of the lower part of the remaining slope with a volume of $0.026 \mathrm{~km}^{3}$. The debris mass collided with the remaining landslide dam and the Chingshui River was once again dammed (Hung, 1980). Following 2 days of rainfall with a cumulative precipitation of $624 \mathrm{~mm}$, a new failure with a volume of $0.040 \mathrm{~km}^{3}$ took place and the landslide dam with a height of $90 \mathrm{~m}$ was overtopped on August 24, 1979. Previous monitoring and timely warning prevented casualties. After the 1979 events, a scarp formed between 650 and $700 \mathrm{~m}$ in elevation (Fig. 2b), the lower part sliding surface of the 1979 rockslide being in the Chinshui shale (Lee et al., 1993).

\subsection{Landslide caused by the Chi-Chi earthquake, 1999}

During the Chi-Chi earthquake on September 21, 1999 , a volume of about $0.125 \mathrm{~km}^{3}$ of rock and soil slid down the Tsaoling dip-slope. From the field investigation, it was found that the remaining slope consisted of four stepping scarps. The dip angles measured on different steps of the dip slope ranged from $12^{\circ}$ to $14^{\circ}$, and the main sliding occurred in the Cholan formation (Fig. 2c). Hung (2000) pointed out that only $0.025 \mathrm{~km}^{3}$ (20\%) of the sliding volume dropped into the valley of the Chingshui River. Remarkably, the vegetation on a few hill slopes downstream of the landslide dam was 
stripped, allegedly because of the air blast released from the impact of the sliding mass (Hung, 2000).

The Chingshui River was once again dammed. The landslide material blocked the gorge of the Chingshui River along a distance of $5 \mathrm{~km}$ (Water ResourcesAgency in Taiwan, 1999). The debris dam had a height of $50 \mathrm{~m}$ upstream and $150 \mathrm{~m}$ downstream. The Tsaoling Lake, having an estimated capacity larger than $0.046 \mathrm{~km}^{3}$, developed (Cheng, 2000). An emergency spillway was constructed through the plugged section of Chingshui River valley.

Finally, overflow of the impounded water commenced on December 22, 1999, without causing damage to the debris dam. Check dams have also been constructed downstream across the Chingshui River, for protection against debris flows due to possible dam failure (which has not happened). The natural dam resulting from the landslide, however, was subject to severe erosion, mainly deep incision of its downstream portion by the Chingshui River.

\section{Geological and structural setting of Tsaoling landslide area}

The study area is located on the west side of the Tsaoling anticline (Fig. 3); the elevations of the mountain slope range from 500 to $1200 \mathrm{~m}$ above sea level (Fig. 4). The geological condition is dominated by sedimentary rocks that dip in the same direction as the slope of the landslide. The Chingshui River flows along the base of the dip slope: it cuts into the toe of the slope and causes the bedding planes to crop out in section. The bedrock formations in this area consist of Tertiary sedimentary rocks (Fig. 3) and include, from base to top: the Miocene Tawo sandstone formation, which is over $1100 \mathrm{~m}$ thick and contains intercalations of shales, the Chinshui shale
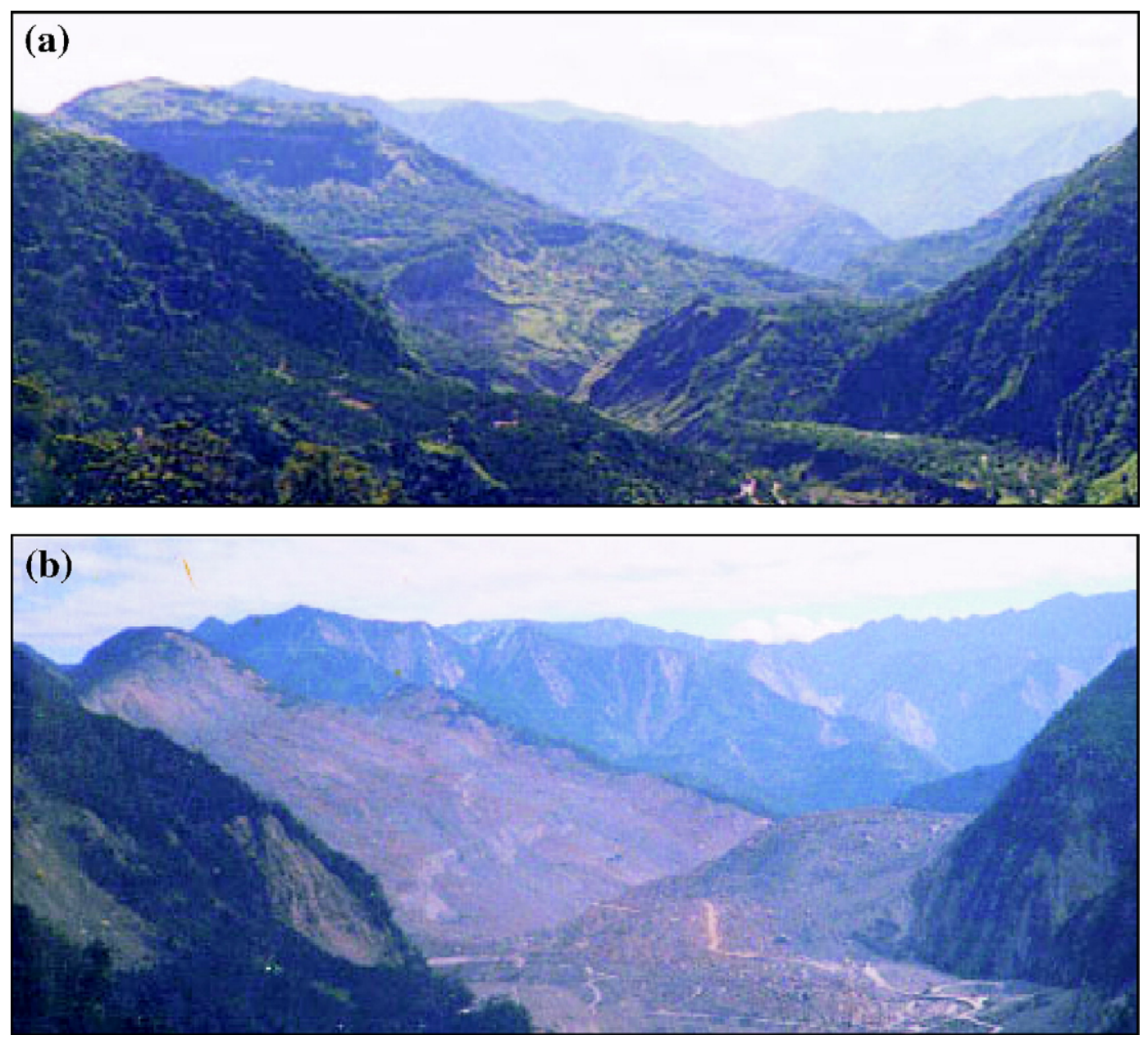

Fig. 4. Overview of the Tsaoling landslide, looking from west to east. (a) Photography taken before the 1999 Chi-Chi earthquake. (b) Photography taken from the same viewpoint after the 1999 Chi-Chi earthquake. 
formation, which is over $110 \mathrm{~m}$ thick and the lower Cholan formation, which consists of fine-grained sandstones and intercalated shales and is over $1000 \mathrm{~m}$ thick (Huang et al., 1983). Recent terrace deposits, landslide deposits and alluvium overlie the bedrock.

The Chinshui shale, in which the historical landslide detachments took place, consists of massive mudstone and shale, with intercalated fine-grained sandstone layers. The Cholan formation, which conformably rests on the Chinshui shale, constitutes most of the landslide mass (Huang et al., 1983).

From the engineering point of view, the Chinshui shale is a friable, silty mudstone with weak cementation that deteriorates readily upon wetting and drying. Surface water could thus infiltrate into the deeper portions of the formation and soften the rock. Before 1999, the landslides resulted from failure of the Chinshui shale that underlies the Cholan formation. The slip surface of the 1999 landslide, however, formed within alternating beds of fine sandstone and shale with ripple lamination or within shales that were all contained in the Cholan formation. This slip surface was smooth and nearly planar, as well as parallel to bedding.

We observed numerous brittle features and carried out data collection on open fractures, faults and bedding at five sites along the detachment surface of the Tsaoling 1999 landslide. Most fractures, especially open fissures, are approximately perpendicular to bedding planes, which are regularly dipping to the southwest, 14 degrees on average. All sites showed open fractures that trend approximately $\mathrm{E}-\mathrm{W}$ and $\mathrm{N}-\mathrm{S}$. The nearly $\mathrm{E}-\mathrm{W}$ fractures generally reflect tension close to the slip direction of the landslide and show clear correlation with the major detachment scarps of the Tsaoling landslide. These fractures and the major scarps left by the landslide are nearly parallel. Fractures trending approximately $\mathrm{N}-\mathrm{S}$ also indicate extension in a direction perpendicular to the slip direction of the landslide, revealing secondary tensile stress. Such phenomena are common not only for landslides, but also for deep-seated tectonic deformations ( $\mathrm{Hu}$ and Anglier, 2004).

We also observed strike-slip and reverse faults, consistent in orientation with local compression induced by the landslide. Most of these faults strike approximately E-W, with steep dips. The existence of both the reverse faults (with some minor folds) and the nearly vertical open tension fissures along the same direction (mainly E-W) does not reveal any mechanical inconsistency, because landsliding induced along-slip extension and compression, depending on the relative displacement of rock sub-masses in the slope.
To summarise, our brittle tectonic analysis revealed that a majority of fractures were related to the landslide process, with structural grains that are principally slopeparallel and slope-perpendicular. Other features were inherited from earlier tectonic deformation and commonly reactivated as open cracks, faults or minor thrusts during the landslide process.

\section{Remote sensing data}

Remote sensing techniques provide powerful tools for landslide monitoring because they offer a synoptic view of the landslide that can be acquired at different time intervals. Aerial photographs have suitable spatial resolution and have been in existence for more than fifty years. Thus, identifying landslides using aerial photographs is common practice (e.g., Wieczorek, 1984). In addition to aerial photogrammetric surveys, topographic measurements are important for obtaining the information of topographic changes after a landslide event. In this study, we use combination of techniques to assess the landslide phenomena, including aerial photogrammetry and airborne laser scanning technique.

To accurately monitor the change of topography in a landslide area, identifiable ground objects are usually selected and employed for measurements, using methods like EDM (Electronic Distance-Measuring) or GPS (Global Positioning System). These methods are applied to specific points, which raise obvious problems because of the discontinuous character and limited density of observations.

The new technology of airborne LiDAR can provide high-precision DEM data, facilitate detection of minor changes in elevation and reveal subtle geomorphic features within an entire area (e.g., Wehr and Lohr, 1999; Chan et al., submitted for publication). The airborne LiDAR technique includes the use of the Global Positioning System, Inertial Navigation System, and a laser distance scanner. Through combined use of laser transmitter with high repeating pulse frequency (RPF) and high speed scanning system, dense

Table 2

Characteristics (precision and grid spacing) of original DEMs

\begin{tabular}{|c|c|c|c|c|}
\hline \multirow[t]{2}{*}{ DEMs } & \multicolumn{2}{|l|}{ Accuracy } & \multirow{2}{*}{$\begin{array}{l}\text { Grid } \\
\text { spacing }\end{array}$} & \multirow[t]{2}{*}{ Data acquisition } \\
\hline & $\begin{array}{l}\text { Open } \\
\text { terrain }\end{array}$ & $\begin{array}{l}\text { Dense } \\
\text { vegetation }\end{array}$ & & \\
\hline 1989 DEM & $\pm 1-2 \mathrm{~m}$ & $\pm 3-5 \mathrm{~m}$ & $40 \mathrm{~m}$ & Photogrammetry \\
\hline 2000 DEM & $\pm 0.5-1 \mathrm{~m}$ & $\pm 1-2 \mathrm{~m}$ & $10 \mathrm{~m}$ & Photogrammetry \\
\hline $\begin{array}{l}2002 \\
\text { LIDAR }\end{array}$ & $\begin{array}{l} \pm 0.15- \\
0.2 \mathrm{~m}\end{array}$ & $\pm 0.2-0.5 \mathrm{~m}$ & $1 \mathrm{~m}$ & $\begin{array}{l}\text { Airborne- } \\
\text { LiDAR }\end{array}$ \\
\hline 2003 DEM & $\pm 0.5-1 \mathrm{~m}$ & $\pm 1-2 \mathrm{~m}$ & $5 \mathrm{~m}$ & Photogrammetry \\
\hline
\end{tabular}


measurements of the terrain surface are obtained, giving a spatial resolution of up to $1 \mathrm{~m}$ horizontal and $0.15 \mathrm{~m}$ vertical (Shih and Peng, 2002). The level of accuracy makes this new technique suitable for measuring change of topography at a decimetre-to-metre scale.

After the 1999 landslide the Tsaoling area has continued to be modified due to severe river erosion, especially during rainstorms. In this study, we analyzed the topographical change during the 4 years that followed the Chi-Chi event, that is, from September 1999 to July 2003 (Table 2). The four datasets used in this study were (1) the Taiwan DEM with $40 \mathrm{~m}$ grid mesh size derived in 1989 from aerial photographs, which shows the situation before the Chi-Chi earth- quake and the 1999 Tsaoling landslide, (2) the Taiwan 2000 DEM with $10 \mathrm{~m}$ grid mesh size derived from aerial photographs after the 1999 event, (3) the local DEM with $1 \mathrm{~m}$ grid mesh size obtained from LiDAR analysis in 2002 and (4) the Taiwan DEM with $5 \mathrm{~m}$ grid mesh size derived from 2003 aerial photographs. Although the horizontal adjustment and the elevation correlation for these different datasets have not been thoroughly done, a preliminary result was accurate enough to reveal significant changes in the topography of the studied area for the different periods under investigation.

The comparisons between the topographic patterns in 1989 and in 2000-2002-2003 (respectively before and after the 1999 Tsaoling landslide event) clearly show a

\section{(a) DEM $198940 \mathrm{~m}$}

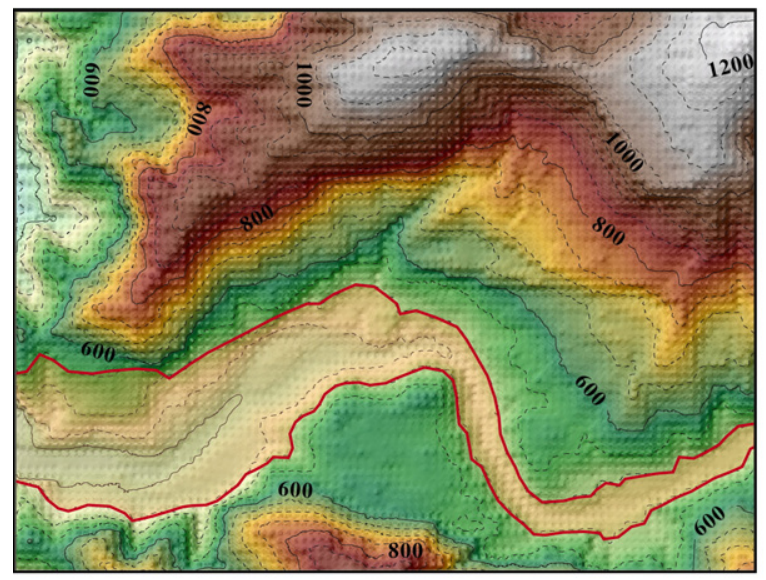

(b) DEM $200010 \mathrm{~m}$

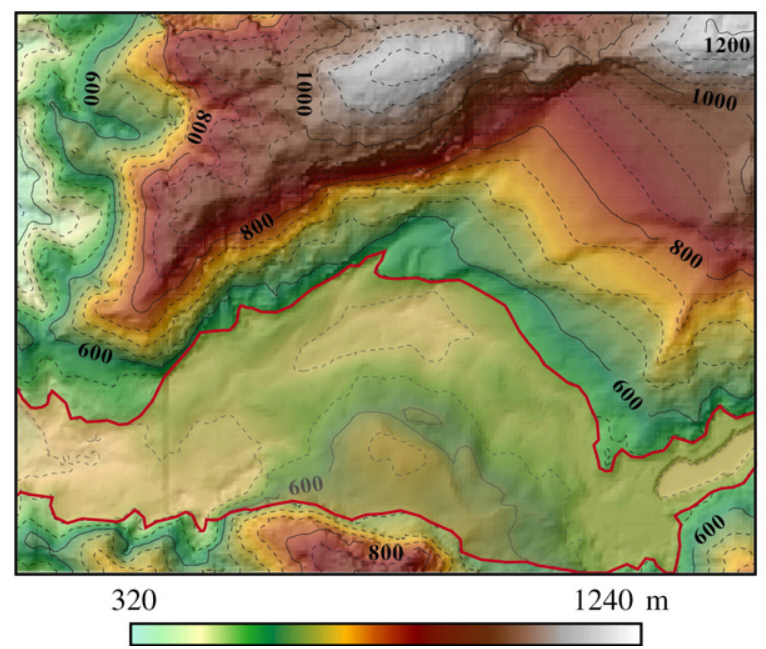

(c) LIDAR $20021 \mathrm{~m}$

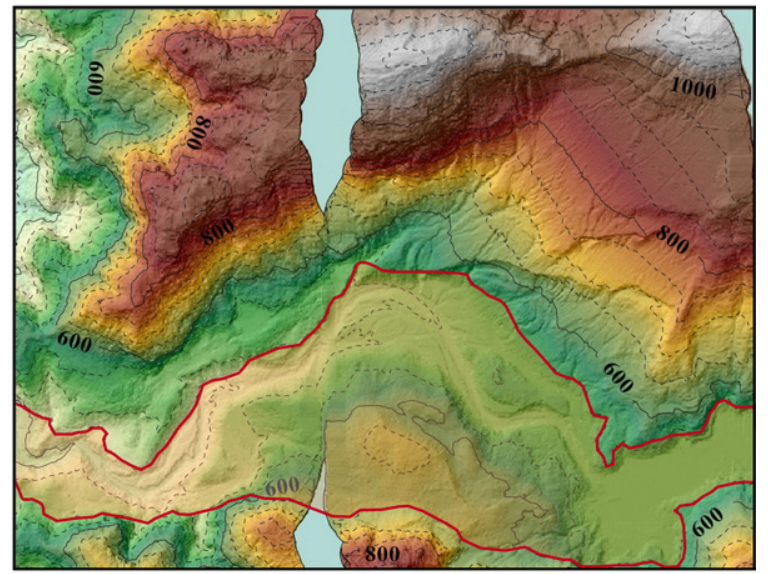

(d) DEM $20035 \mathrm{~m}$

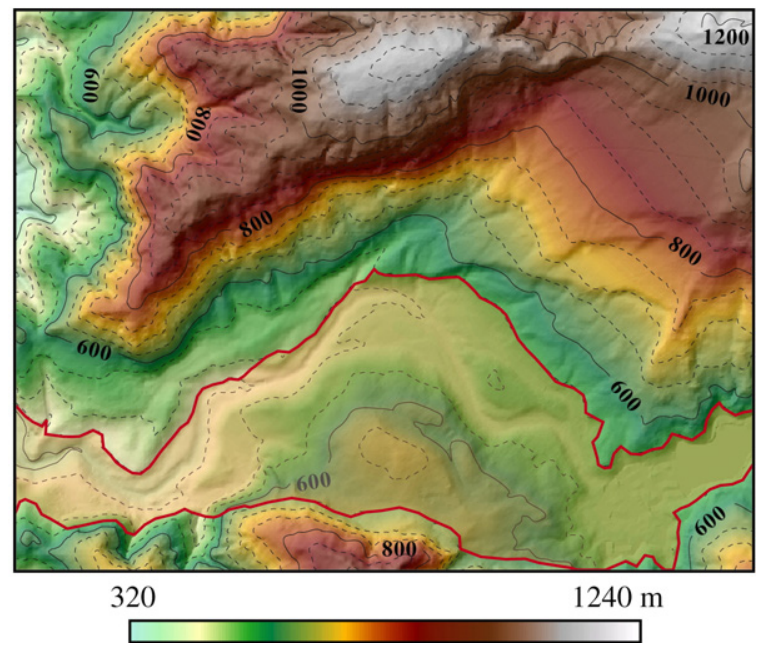

Fig. 5. Topographic changes of the Tsaoling landslide induced by the 1999 Chi-Chi earthquake, based on different digital elevation models (DEM), with 50 contour intervals. Deposit areas indicated by red-solid line. (a) Taiwan $40 \mathrm{~m}$ DEM obtained from 1989 aerial photographs. (b) Taiwan $10 \mathrm{~m}$ DEM obtained from 1999 aerial photographs after Chi-Chi earthquake. (c) $1 \mathrm{~m}$ airborne-LiDAR-derived DEM, 2002. (d) Taiwan $5 \mathrm{~m}$ DEM obtained from 2003 aerial photographs after the Chi-Chi earthquake. 
Table 3

Comparisons between different post-1999 situations (in 2000, 2002 and 2003, with the $10 \mathrm{~m}, 5 \mathrm{~m}$ and $1 \mathrm{~m}$ grids respectively) and the prelandslide situation (based on the $198940 \times 40 \mathrm{~m}$ DEM)

\begin{tabular}{lllll}
\hline Time & $\begin{array}{l}\text { Scar } \\
\text { volumes } \\
\left(V_{1}\right)\end{array}$ & $\begin{array}{l}\text { Deposit } \\
\text { volumes } \\
\left(V_{2}\right)\end{array}$ & $\begin{array}{l}\text { Erosion } \\
\text { volumes } \\
\left(V_{\mathrm{e}}\right)\end{array}$ & $\begin{array}{l}\text { Altitude } \\
\text { correction } \\
\text { relative to } \\
1989\end{array}$ \\
\hline $1989-2000$ & $0.1239 \mathrm{~km}^{3}$ & $0.1402 \mathrm{~km}^{3}$ & $0.0098 \mathrm{~km}^{3}$ & $-7.93 \mathrm{~m}$ \\
$1989-2002$ & $0.1246 \mathrm{~km}^{3}$ & $0.1170 \mathrm{~km}^{3}$ & $0.0330 \mathrm{~km}^{3}$ & $-6.78 \mathrm{~m}$ \\
$1989-2003$ & $0.1250 \mathrm{~km}^{3}$ & $0.1095 \mathrm{~km}^{3}$ & $0.0405 \mathrm{~km}^{3}$ & $+8.04 \mathrm{~m}$ \\
\hline
\end{tabular}

Note that erosion from 1989 to 1999 is minor with respect to landslide volume and post-landslide erosion, and hence neglected. Scar, deposit and eroded volumes ( $V_{1}, V_{2}$ and $V_{\mathrm{e}}$, respectively) illustrated in Fig. 6a.

major mass deficit in the mountain slope (near the northeast corner of the maps in Fig. 5) and a mass excess in the Chingshui River valley (near the centre of the maps). To examine the elevation differences in more detail and quantify the volume transfer involved in the 1999 event, we carried out comparisons between these topographic datasets (Fig. 5).

\section{Volumetric analysis of landslide}

The 1989 DEM was the single source of quantitative information available and used in our work to depict the situation prior to the 1999 Tsaoling landslide. However, topographic surveys and fracture data collection were carried out from 1989 to 1993 and revealed that little surface change occurred in the Tsaoling area during this period (Lee et al., 1993). Note that for the purpose of comparisons the 1989 DEM was used to ortho-rectify three aerial photograph sets acquired in 1989, 2000 and 2003. In addition, the point clouds taken by airborne LiDAR were used for correlation purposes. To gather and compare the digital information available for the Tsaoling landslide area, we used ArcGIS tools, which enabled the operations described below, especially the volume calculations.

Each original photograph or image had a specific scale. To perform calculations with the different versions of DEM with a single homogenous baseline, we selected five sub-areas in order to correlate the average altitudes. The sub-areas were defined according to the presence of clear topographic features and the absence of significant changes during the periods analyzed. Thus all homologous control points within areas of overlap between images could be correlated and positioned. This correlation and adjustment process was crucial for further volume determinations, which proved to be sensitive to uniform offsets between elevations models (even a minor uniform offsets produces large volume changes over the whole area). The grids were then interpolated, based on the 1989 situation (before the sliding event), over all points in the overlap area of stereoscopic images. Subsequently, they were registered and re-sampled within a single $1 \mathrm{~m}$ grid (that of the 2002 LiDAR DEM) to allow comparison between all the spatial data. These data were also converted into a common TWD67 coordinate system (the reference system commonly used in Taiwan).

The DEM mesh size used for volume calculations was influenced by that of the less accurate DEM. This means that the comparison between the situations before and after the 1999 Tsaoling landslide principally depends on the relatively large mesh size of the 1989 DEM, both horizontal (the $40 \mathrm{~m}$ grid) and vertical. Altitude comparisons between different DEMs (2000, 2002 and 2003) were all made with reference to the 1989 DEM (Table 3). Altitude corrections were based on control areas unaffected by the landslide and the subsequent topographic changes. The corrected DEMs were used for topographic correlations between images and for volume determinations. The uncertainties of the 1989 Taiwan DEM are the largest and range between $9 \%$ and $11 \%$. However, the results are significant enough to reveal the changes associated with the 1999 landslide. The comparisons between the post-1999 situations (with the $10 \mathrm{~m}, 5 \mathrm{~m}$ and $1 \mathrm{~m}$ grids) has benefited from better resolution, which was useful to characterize the post-landslide evolution, especially to quantify the river erosion.

The volume change of the Tsaoling landslide event shortly after the Chi-Chi earthquake could be estimated based on a comparison between the photogrammetryderived $40 \times 40 \mathrm{~m}$ pre-landslide 1989 DEM and the $10 \times 10 \mathrm{~m}$ post-landslide 2000 DEMs. According to this comparison, the scar volume was about $0.126 \mathrm{~km}^{3}$; the deposit volume was about $0.150 \mathrm{~km}^{3}$, which suggests a volume increase of $19 \%$ during the landslide event, as a consequence of the decompaction during the landsliding (Cheng, 2000). Moreover, this coseismic volume change provided a reference for studying volume change due to later river erosion.

For instance, the volume change indicated by the comparison between the 1989 DEM and the LiDARbased 2002 DEM involves a mass transfer related to postlandslide. This transfer is clearly illustrated by the color scale in Fig. 6b, which highlights both the topographic deficit (upslope) and the topographic excess (downslope) in volume. Our calculation, based on the situation in April 2002 compared with that of 1989 , revealed a scar volume, $V_{1}$ (Fig. 6a), of about $0.1246 \mathrm{~km}^{3}$, by $0.0014 \mathrm{~km}^{3}$ less than the coseismic value $\left(0.126 \mathrm{~km}^{3}\right)$, and a deposit 
volume, $V_{2}$, of about $0.1170 \mathrm{~km}^{3}$, by $0.0330 \mathrm{~km}^{3}$ smaller than the coseismic value $\left(0.150 \mathrm{~km}^{3}\right)$. And comparison with coseismic volume also reveals that the downslope excess volume is larger than the upslope missing volume, which reflects significant decompaction during the 1999 Tsaoling landslide event. The difference in deposit volume, about $22 \%$, probably reflects the amount of erosion that affected the landslide area 2.5 years after the 1999 event, that is, the removal of a volume of landslide debris by the river.

The difference in scar volume, about $1 \%$, is within the range of technical uncertainties, and hence not significant. It is thus impossible to demonstrate that this difference really results from the local debris accumu-
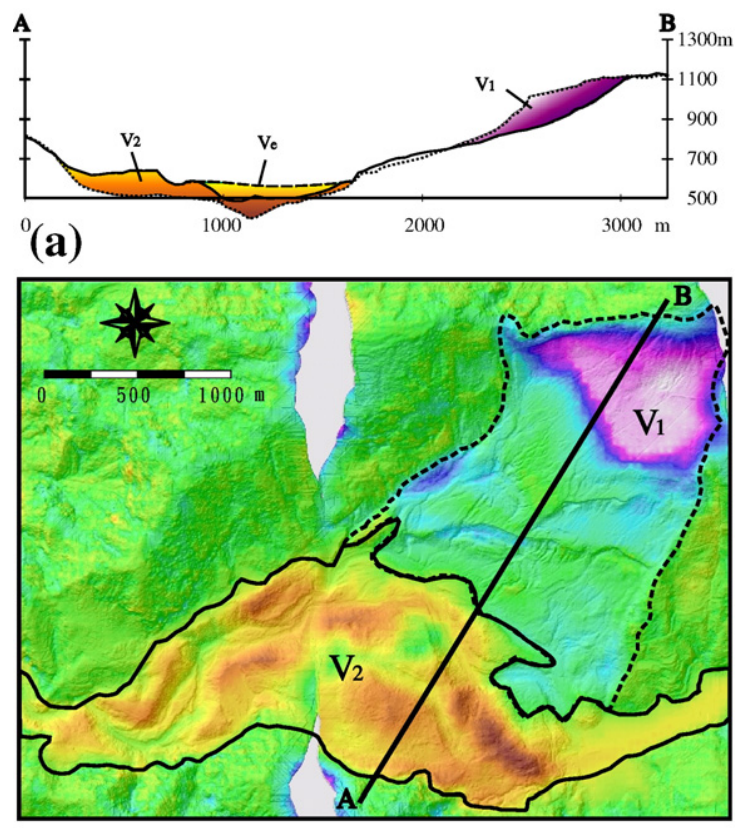

(b)

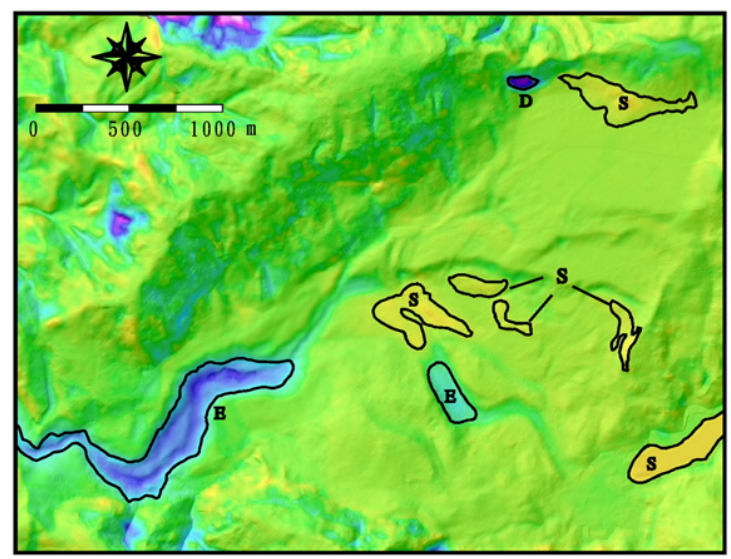

(c) lation observed. However, the uncertainties, which mainly originate from the $40 \times 40 \mathrm{~m}$ pre-landslide DEM, remain large in this calculation. As a result, this determination is questionable; moreover, it is certainly biased by our assumption of negligible erosion from 2000 to 2002 . This evaluation is done in a more rigorous way in the Discussion and conclusions Section, based on the comparison between the post-landslide DEMs, which are not affected by the relatively poor resolution of the 1989 DEM. However, the volume comparison does not accurately reflect the amount of decompaction because it also involves the erosion that occurred before and after the Tsaoling landslide. This implies that the actual amount of decompaction is larger than that calculated from the 1989 and 2002 data.

The value of about $0.03 \mathrm{~km}^{3}$ for the eroded volume, inferred from the difference in the deposit volumes between 2000 and 2002 compared with the coseismic deposit volume, can be considered as a maximum. This is because it includes the pre-landslide erosion between 1989 and 1999, albeit limited according to the field observation and analysis of aerial photographs.

According to our calculation, the excess volume of disrupted material before river erosion, $V_{2}+V_{\mathrm{e}}$ in Fig. 6a, is $0.1514 \mathrm{~km}^{3}$ ( $V_{\mathrm{e}}$ being the eroded volume). Comparing this excess volume with the scar volume, $V_{1}$ (Fig. 6a), we write $V_{1} \delta=V_{2}+V_{\mathrm{e}}$, where $\delta$ is the syn-sliding decompaction coefficient. Using the 2002 cut volume, $0.1246 \mathrm{~km}^{3}$ for $\mathrm{V}_{1}$, one obtains $\delta=1.22$. This suggests a volume increase of $22 \%$ during the landslide event, which is larger

Fig. 6. Results of volume change calculations and relevant explanation, 1999 Tsaoling landslide area. (a) Presentation of the scar, deposit and eroded volumes $\left(V_{1}, V_{2}\right.$ and $V_{\mathrm{e}}$, respectively) in schematic cross section A-B, with location in (b); 1989 pre-landslide profile as dotted line, late 1999 post-landslide profile as dashed line, 2002 profile as solid line. Note that $V_{1} \delta=\left(V_{2}+V_{\mathrm{e}}\right), \delta$ being the coefficient of syn-sliding decompaction. (b) Estimated volume change after the 1999 Tsaoling landslide, based on the difference between the $198940 \times 40 \mathrm{~m}$ DEM and the 2002 LiDAR DEM. Scar and deposit areas indicated by purple-blue and orange-yellow domains respectively, areas without significant topographic change in green (see colour scale below the image). Note section A-B shown in (a); $V_{1}$ and $V_{2}$ stand for scar and deposit volumes, respectively. (c) Estimated volume change after the 1999 Tsaoling landslide, based on the difference between the $200010 \times 10 \mathrm{~m} \mathrm{DEM} \mathrm{(from} \mathrm{aerial} \mathrm{photographs)}$ and the $20035 \times 5 \mathrm{~m}$ DEM (from aerial photographs). Volume deficit and excess indicated by blue and yellow respectively, areas without significant topographic change in green (see colour scale below image). E, area with topographic deficit (river erosion); S, area with topographic excess (river sediment fill in landslide dam lake and debris accumulation zones below landslide escarpments); D, local topographic deficit from rock fall. Other explanations in text. (For interpretation of the references to colour in this figure legend, the reader is referred to the web version of this article.) 
than, but consistent with, that inferred from the coseismic volume changes (19\%). The discrepancy may result from both the differences DEMs and the unknown relationship between pre-landslide and post-landslide erosion. Note that the landslide materials moving down the slope during the erosion stage had already undergone bulking during the coseismic landslide event.

\section{Discussion and conclusions}

In general, the erosion and denudation rates in Taiwan are influenced by the subtropical climate of the island, with four typhoons per year and precipitation of $2515 \mathrm{~mm} /$ year on average. They are also influenced by the frequent earthquakes and the rapid fluvial bedrock incision induced by active uplift (Li, 1976; Hovius et al., 2000; Dadson et al., 2004). The change in denudation rate resulted from the $\mathrm{Chi}-\mathrm{Chi}$ earthquake requires investigations into other thousands of landslides occurred in Taiwan. It may not be possible to estimate the island-wide denudation rate using the data from the Tsaoling landslide alone. The Tsaoling landslide history provides case examples to evaluate the importance of geological factors in landslide occurrence and the influence of landslides on water resource planning and hazard assessment. Increasingly detailed investigations have been carried out since 1980, involving remote sensing and aerial photograph analyses, field surveys and in situ monitoring and laboratory tests (Hung et al., 2002). The construction of a replacement reservoir at the landslide site is discussed, but a possible reactivation of the Tsaoling landslide raises obvious concerns about such plans.

The high-resolution digital elevation model (DEM) derived from the recent airborne LiDAR data enabled us to map and analyse in more detail than before the destructive Tsaoling landslide triggered by 1999 ChiChi earthquake. Geological and morphological observations of the sliding surface and landslide deposits led to better describe the landslide and to quantify its volume. The LiDAR data allowed comprehensive investigation of the morphological features present along the sliding surface and in the deposit areas.

In the Chingshui downstream, we compared the aerial photographs before and after the Toraji typhoon in 2001. The downstream area shows increased river width, decreased river curvature, shifted and branched river course, and buried vegetations with deposited sand and soils. The area of flooded regions and fluvial channels has increased about $26.8 \%$ in the downstream before the Toraji typhoon.

In our study, two main difficulties were encountered: the absence of high resolution LiaDar data before the
1999 landslide and the dates of the different DEMS, which did not coincide with the main landslide event. For this reason, we had to carry out multiple comparisons and extrapolations in order to distinguish pre-landslide, synlandlside and post-landslide volume changes. From the technical point of view, because the LiDAR data did not exist before the landslide, in these comparisons we had to combine the recent LiDAR data with earlier topographic data, which are numerous but generally less accurate. These earlier data were issued from aerial photographs, topographic maps and satellite images. We thus evaluated the volumetric changes before, during and after the 1999 Tsaoling catastrophic landslide event. First, regarding the landslide scar volume, our analysis provides a value $\left(0.124-0.125 \mathrm{~km}^{3}\right.$, see Table 3$)$, similar to the values obtained by other means: $0.125 \mathrm{~km}^{3}$ from the analyses of SPOT images (Liao, 2000) and $0.126 \mathrm{~km}^{3}$ from analyses of aerial photographs (Cheng, 2000). Because our comparisons between the 1989 DEM and the different post-landslide DEMs (2000, 2002 and 2003) yielded results that can be considered identical within the range of uncertainties, we infer that the amount of erosion that affected the scar area of the landslide from September 1999 to June 2003 was minor.

Regarding the deposit volume of the 1999 Tsaoling landslide, our conclusions are quite different. The comparison between the deposit volume calculated using the DEM of June 2003 and the corresponding coseismic volume, $0.150 \mathrm{~km}^{3}$, as determined by Cheng (2000), indicates that $0.0405 \mathrm{~km}^{3}$, i.e. about $37 \%$ of the initial deposit volume, has been removed by erosion after the landslide event. This difference is much larger than the uncertainties in volume determinations, and hence should be regarded as significant.

We also carried out a comparison between the 2003 and 2000 DEMs with $5 \mathrm{~m}$ and $10 \mathrm{~m}$ grid mesh sizes, respectively. Whereas the scar volume does not change significantly, the deposit volume decreases, giving a deficit of $0.0307 \mathrm{~km}^{3}$. The comparison between the two volume decrease values suggests that erosion has removed a volume of $0.0098 \mathrm{~km}^{3}$ during the first 10 months after the landslide, and $0.0307 \mathrm{~km}^{3}$ during the following 3 years. The corresponding annual erosion rates are $0.012 \mathrm{~km}^{3} /$ year and $0.010 \mathrm{~km}^{3} /$ year. It would be quite logical to expect rapid erosion just after the dam emplacement and decreasing rate of erosion later. However, our period of post-landslide observation is only few years long, so that a significant decrease in erosion rate may be difficult to detect through a simple comparison between the 10 months after the earthquake and the following 3 years. It is to be noted that a major typhoon (the Toraji typhoon, July 2001), which hit the area during the investigation period, probably 
resulted in an increased in the average erosion rate. From these determinations we conclude that during the four years after the event an erosion rate of about $0.01 \mathrm{~km}^{3} /$ year in the deposit area of the 1999 landslide is a reasonable value. Since the deposit area is about $2.8 \mathrm{~km}^{2}$, the above value would imply a denudation rate of about $3.6 \mathrm{~m} / \mathrm{year}$ on the average. However, post-1999 observations in the landslide area indicated the presence of a deep local incision of the disrupted rock mass in the river valley and moderate erosion in the neighbouring portions of the landslide mass, so that the average value given above has little significance.

Fig. 6c shows that the greatest amount of the erosion occurred in a narrow channel in the Western portion of the landslide deposit along the Chingshui River (deficit area "E" in Fig. 6c). The comparison between the two DEMs (2000 and 2003) in this particular a indicates that the incision is locally deeper than about $60 \mathrm{~m}$, a surprising high value confirmed by field observations. Our analysis indicates that the main incision domain covers an area of $0.23 \mathrm{~km}^{3}$. The corresponding eroded volume is approximately $0.01 \mathrm{~km}^{3}$. According to these values the river erosion has been very active near the bottom of the valley, in the downstream portion of the dammed area, during the few years following the 1999 landslide event (with local rates up to about $20 \mathrm{~m} /$ year).

Not surprisingly, the comparison between the 2000 and 2003 DEMs also reveal areas with excess volume ("S" in Fig. 6c), indicating river sediment infill upstream of the 1999 landslide dam in the valley and debris accumulation below the landslide escarpments on the Tsaoling Mountain slope.

The calculated eroded volumes (about $0.01 \mathrm{~km}^{3} /$ year in the deposit area of the landslide, for a period of nearly 4 years) are very large with respect to the size of the affected area, giving very high local denudation rates. This shows how effective the landslide process may be, as an agent of rock mass disruption that facilitates subsequent erosion. We infer that the weak mechanical properties of the landslide mass significantly influenced the long-term denudation rate in the study area. Finally, the Tsaoling landslide history reveals that the recurrence probability of major landslide events is very high. This clearly deserves careful consideration as far as hazard mitigation is concerned.

\section{Acknowledgements}

The LiDAR raw data were provided by the Agricultural and Forestry Aerial Survey Institute of Taiwan. This research was supported by the TaiwanFrance co-operation in Earth Sciences (French Institute in Taipei-IFT and National Science Council of TaiwanNSC), and by the French CNRS (PICS Taiwan). We thank Mr. Yan I-Ho for his help, and Prof. Shih T. Y for supplying the information about airborne LiDAR data. Dr. David Keefer, an anonymous reviewer and guest editors of this special issue, Janusz Wasowski and Vincenzo Del Gaudio, provided constructive comments.

\section{References}

Angelier, J., Lee, J.-C., Chu, H.-T., Hu, J.-C., Lu, C.-Y., Chan, Y.-C., Lin, T.-J., Font, Y., Deffontaines, B., Tsai, Y.-B., 2001. Le Séisme de Chi-Chi (1999) et sa place dans l'orogène de Taiwan. C. R. Geosciences 333, 5-21.

Central Geological Survey, 1999. Surface ruptures along the Chelungpu fault during the Chi-Chi earthquake of Taiwan, 1:25 000, 4 maps (in Chinese).

Central for Space and Remote Sensing Research, 1989. 1/5000 Digital Terrain Model. National Central University, Taiwan.

Chan, Y.C., Chen, Y.G., Shih,Y., Huang, C. submitted for publication. Characterizing the Hsincheng active fault in northern Taiwan using airborne LiDAR data: detailed geomorphic features and their structural implications. Journal of Asian Earth Sciences.

Chang, L.-S., 1951. Topographic features and geology in the vicinity of the nature reservoir near Tsao-Ling. Taiwan Reconstruction Monthly 1, 22-27 (in Chinese).

Charlton, M., Large, A.R.G., Fuller, I.C., 2003. Application of airborne LiDAR in river environments: the River Coquet, Northumberland, UK. Earth Surface Processes and Landforms 28, 299-306.

Chen, W.-S., Huang, B.-S., Chen, Y.-G., Lee, Y.-H., Yang, C.-N., Lo, C.-H., Chang, H.-C., Sun, Q.-C., Huang, N.-W., Lin, C.-C., Sung, S.-H., Lee, K.-J., 2001a. 1999 Chi-Chi earthquake: a case study on the role of thrust-ramp structures for generating earthquake. Bulletin of Seismicity of the Social America 91, 986-994.

Chen, Y.-G., Chen, W.-S., Lee, J.-C., Lee, Y.-H., Lee, C.-T., Chang, H.-C., Lo, C.H., 2001b. Surface rupture of 1999 Chi-Chi Earthquake yields insights on active tectonics of central Taiwan. Bulletin of Seismicity of the Social America 91, 977-985.

Chen, T.-C., Lin, M.-L., Hung, J.-J., 2003. Pseudostatic analysis of Tsao-Ling rockslide caused by $\mathrm{Chi}-\mathrm{Chi}$ earthquake. Engineering Geology 71, 31-47.

Cheng, H.-H., 2000. Photogrammetric Digital Data Processing of Tsao-Ling Big Landslide. ACRS Taipei, Conference Poster.

Chigira, M., Wang, W.-N., Furuya, T., Kamai, T., 2003. Geological causes and geomorphological precursors of the Tsaoling landslide triggered by the 1999 Chi-Chi earthquake, Taiwan. Engineering Geology 68, 259-273.

Chung, J.K., Shin, T.C., 1999. Implication of the rupture process from the displacement distribution of strong ground motions recorded during the 21 September 1999 Chi-Chi, Taiwan earthquake. T.A.O., vol. 10, pp. 777-786.

Dadson, S.J., Hovius, N., Chen, W.-B., Dade, Lin, J.-C., Hsu, C.-W., Lin, M.-J., Horng, Chen, T.-C., Milliman, J., Stark, C.P., 2004. Earthquake-driven increase in sediment delivery from an active mountain belt. Geology 32, 733-736.

Hovius, N., Stark, C.P., Chu, H.-T., Lin, J.-C., 2000. Supply and removal of sediment in a landslide-dominated mountain belt: Central Range, Taiwan. Journal of Geology 108, 73-89. 
Hsu, M.T., 1980. Earthquake catalogues in Taiwan (from 1644 to 1979). Center for Earthq. Eng. Res. Report, vol. 69-01 (in Chinese).

Hsu, T.-L., Leung, H.-P., 1977. Mass movements in the Tsaoling area, Yunlin-Hsien, Taiwan. Process Geology Social China 20, 114-118.

Hu, C.-J., Angelier, J., 2004. Stress permutations: Three-dimensional distinct element analysis accounts for a common phenomenon in brittle tectonics. JGR 109, B09403, doi:10.1029/2003JB002616.

Huang, C.-S., Ho, H.-C., Liu, H.-C., 1983. The egology and landslide of Tsao-Ling area. Yunlin Hsien, Taiwan. Bulletin Chintral Geology Survery 2, 95-112 (in Chinese).

Hung, J.-J., 1980. A study on Tsao-Ling rockslides, Taiwan. Journal of Engineering Environment 1, 29-39.

Hung, J.-J., 2000. Chi-Chi earthquake induced landslides in Taiwan. Earthquake Engineering and Engineering Seismology 2, 25-32.

Hung, J.-J., Lee, C.-T., Lin, M.-L., 2002. Tsao-Ling rockslides, Taiwan, catastrophic landslides: effects, occurrence, and mechanisms. Geological Society of America Reviews in Engineering Geology 15, 91-115.

Joinville, O., Ferrand, B., Roux, M., 2002. Levé laser aéroporté: état de l'art, traitement des données et comparation avec des système imageurs. Bulletin SFPT 166, 72-81 (in French).

Kamai, T., 1942. Untersuchung des neuen Sees gebildet infolge des Erdbebens vom Jahre 1941 in Taiwan (Fromosa). Bulletin Earthquake Research Institute University Tokyo 21, 317-325.

Kao, H., Chen, W.-P., 2000. The Chi-Chi earthquake sequence: active out-of-sequence thrust faulting in Taiwan. Science 30, 2346-2349.

Keefer, D.K., 1984. Landslides caused by earthquakes. Geology Social America Bulletin 95, 406-421.

Lee, C.-T., Hung, J.-J., Lin, M.-L., Tsai, L.-Y., 1993. Engineering geology investigations and stability assessments on Tsao-Ling landslide area. A Special Report Prepared for Sinotech Engineering Consultants. 224 pp. (in Chinese).

Lee, J.-C., Chu, H.-T., Angelier, J., Chan, Y.-C., Hu, J.-C., Lu, C.-Y., Rau, R.-J., 2002. Geometry and structure of northern surface rupture of the $1999 M_{\mathrm{w}}=7.6 \mathrm{Chi}-\mathrm{Chi}$, Taiwan earthquake: influence from inherited Fold Belt structures. Journal of Structure Geology 24, 173-192.

Li, Y.-H., 1976. Denudation of Taiwan island since the Pleistocene epoch. Geology 4 (2), 105-107.

Liao, H.-W., 2000. Landslides triggered by Chi-Chi earthquake. Master Thesis, Institute of Geophysics, National Central University, Chung-Li, 90 pp. (in Chinese).

Ma, K.F., Lee, C.T., Tsai, Y.B., Shin, T.C., Mori, J., 1999. The ChiChi, Taiwan earthquake: large surface displacements on an inland thrust fault. EOS, Transaction 80, 605-611.

Priestnall, G., Jaafar, J., Duncan, A., 2000. Extracting urban features from LiDAR digital surface models. Computers, Environments and Urban Systems 24, 65-78.

Shih, T.-Y., Peng, M.-H., 2002. Preliminary results of mapping earthquake hazard with Airborne LiDAR system trials. 21th Annual Meeting of Geodesy, pp. 449-456.

Tai-Pei Observatory, 1942. Report on Chia-Yi Earthquake on 17th Dec. 1941. Taiwan Governor's Office. 227 pp. (in Japanese).

Water Resources Agency, Ministry of Economic Affaire, 1999. The Final Report of Current Response Measures for Tsao-Ling Landslide Formed in 921 Earthquake, Taiwan. R.O.C. (in Chinese).

Water Resources-Agency, Ministry of Economic Affairs, 2002. Hydrological Year Book of Taiwan, Taiwan. R.O.C. (in Chinese).

Wehr, A., Lohr, U., 1999. Airborne laser scanning - an introduction and overview. ISPRS JPRS 54, 68-82.

White, S.A., Wang, Y., 2003. Utilizing DEMs derived from LiDAR data to analyze morphologic change in the North Carolina coastline. Remote Sensing of Environment 85, 39-47.

Wieczorek, G.F., 1984. Preparing a detailed landslide-inventory map for hazard evaluation and reduction. Bulletin of the Association of Engineering Geologists 21, 337-342.

Yu, S.-B., Chen, H.-Y., Kuo, L.-C., 1997. Velocity field of GPS stations in the Taiwan area. Tectonophysics 274, 41-59. 